\title{
Erratum to: Lifestyle choices and mental health: a representative population survey \\ (1) CrossMark
}

\author{
Julia Velten ${ }^{1 *}$, Kristen L Lavallee ${ }^{1,2}$, Saskia Scholten ${ }^{1}$, Andrea Hans Meyer ${ }^{2}$, Xiao-Chi Zhang ${ }^{1}$, Silvia Schneider ${ }^{1}$ \\ and Jürgen Margraf ${ }^{1}$
}

Due to a technical error, a 21-item version of the Depression Anxiety and Stress Scales (DASS-42; Lovibond \& Lovibond, 1995) which is not identical to the DASS-21 validated by Henry and Crawford (2005) was used in our study [1]. Ten items of the DASS version that was used in our study [1] were identical to the items of the original DASS-21, the remaining eleven items were part of the DASS-42, but not of the DASS-21 by Crawford and Henry (2005) [2]. In order to put the results of our paper into perspective, we have conducted an additional study that aimed to investigate the comparability of our 21 -item version with the original DASS-21 that has been validated by Henry and Crawford (2005) [2].

A total of 1,031 individuals (47.9\% male) participated in a web-based survey, which included the DASS-42. Mean age of the participants was 48 years $(S D=15.26)$.

Comparisons between the original DASS-21 and the version that was used in our study revealed that both scales were highly similar. Correlations between the original DASS-21 subscales and the subscales of the version that was used in our study were very high $(r=.97, p<.001$ for depression, $r=.93, p<.001$ for anxiety, and $r=.94$, $p<.001$ for stress). Differences in the mean scores for all subscales were negligible to small (Cohen's d was 0.06 for depression, 0.07 for anxiety, and 0.24 for stress). The internal consistency of our version ( $\alpha=.93$ for depression, $\alpha=.85$ for anxiety, and $\alpha=.90$ for stress) was also comparable to the original DASS-21 ( $\alpha=.93$ for depression, $\alpha=.86$ for anxiety, and $\alpha=.91$ for stress).

Upon referring to our article [1], please acknowledge that we have used a 21-item version of the DASS-42 that is similar but not identical with the scale that has been validated by Crawford and Henry (2005) [2].

\footnotetext{
* Correspondence: julia.velten@rub.de

${ }^{1}$ Faculty of Psychology, Department of Clinical Psychology and

Psychotherapy, Mental Health Research and Treatment Center,

Ruhr-Universität Bochum, Massenbergstrasse 9-13, D-44787 Bochum,

Germany

Full list of author information is available at the end of the article
}

\author{
Author details \\ ${ }^{1}$ Faculty of Psychology, Department of Clinical Psychology and \\ Psychotherapy, Mental Health Research and Treatment Center, \\ Ruhr-Universität Bochum, Massenbergstrasse 9-13, D-44787 Bochum, \\ Germany. ${ }^{2}$ Department of Psychology, University of Basel, Basel, Switzerland.
}

Received: 19 January 2016 Accepted: 19 January 2016 Published: 22 January 2016

\section{References \\ 1. Velten J, Lavallee KL, Scholten S, Hans Meyer A, Zhang XC, Schneider S, et al. Lifestyle choices and mental health: a representative population survey. BMC Psychology. 2014;2:58. doi:10.1186/s40359-014-0055-y. \\ 2. Henry JD, Crawford JR. The short-form version of the Depression Anxiety Stress Scales (DASS-21): construct validity and normative data in a large non-clinical sample. British Journal of Clinical Psychology. 2005;44(2):227-39.}

Submit your next manuscript to BioMed Central and we will help you at every step:

- We accept pre-submission inquiries

- Our selector tool helps you to find the most relevant journal

- We provide round the clock customer support

- Convenient online submission

- Thorough peer review

- Inclusion in PubMed and all major indexing services

- Maximum visibility for your research

Submit your manuscript at www.biomedcentral.com/submit
Oramencecome 